\title{
The role of amyloid beta clearance in cerebral amyloid angiopathy: more potential therapeutic targets
}

\author{
Xue-mei Qi and Jian-fang Ma*
}

\begin{abstract}
Cerebral amyloid angiopathy (CAA) is characterized by the deposition of amyloid $\beta$-protein $(A \beta)$ in the leptomeningeal and cortical blood vessels, which is an age-dependent risk factor for intracerebral hemorrhage (ICH), ischemic stroke and contributes to cerebrovascular dysfunction leading to cognitive impairment. However clinical prevention and treatment of the disease is very difficult because of its occult onset and severity of the symptoms. In recent years, many anti-amyloid $\beta$ immunotherapies have not demonstrated clinical efficacy in subjects with Alzheimer's disease (AD), and the failure may be due to the deposition of $A \beta$ in the cerebrovascular export pathway resulting in further damage to blood vessels and aggravating CAA. So decreased clearance of $A \beta$ in blood vessels plays a crucial role in the development of $C A A$ and $A D$, and identification of the molecular pathways involved will provide new targets for treatment. In this review, we mainly describe the mechanisms of $A \beta$ clearance through vessels, especially in terms of some proteins and receptors involved in this process.
\end{abstract}

Keywords: Cerebral amyloid angiopathy, Alzheimer's disease, Amyloid $\beta$-protein, Clearance

\section{Background}

Cerebral amyloid angiopathy (CAA) is the second reason (after hypertension) causing cerebral hemorrhage in the elderly, accounting for $15-40 \%$ of non-traumatic cerebral hemorrhage in the elderly with a mortality of $30-50 \%$ [1]. Occasionally, CAA can be presented as cerebral ischemic attack, cognitive dysfunction and cerebral vasculitis [2, 3]. In addition, CAA is commonly found in Alzheimer's disease (AD) and nearly $80 \%$ of $\mathrm{AD}$ patients are accompanied by CAA [4].

The main pathological feature of CAA is the deposition of amyloid $\beta$-protein $(A \beta)$ in the tunica media and adventitia of the arterioles and/or capillaries in the cerebral cortex and leptomeninges [5]. A $\beta$ deposited in AD senile plaques is mainly $A \beta_{42}$, however it's usually $A \beta_{40}$ that deposited in the vascular wall of CAA. Sporadic CAA is commonly classified into two categories based on the presence or absence of $A \beta$ on capillaries: CAA-type 1 is defined if the deposition of $A \beta$ on cortical capillaries

\footnotetext{
* Correspondence: majifa@hotmail.com

Department of Neurology \& Institute of Neurology, Ruijin Hospital Affiliated to Shanghai Jiaotong University School of Medicine, Shanghai 200025, China
}

beside leptomeningeal, cortical arteries and arterioles, and CAA -type 2, not involving cortical capillaries.

In physiological conditions, human brain can produce $A \beta$ without abnormal accumulation because $A \beta$ can be moved out through several mechanisms quickly and effectively: (1) uptake and degradation by glial cells; (2) degradation by proteolytic enzymes; (3) clearance through blood brain barrier (BBB); (4) interstitial fluid bulk-flow clearance (perivascular drainage or clearance by glymphatic pathway); (5) complement-related clearance. One proposed pathogenesis of CAA is that inefficient $A \beta$ clearance leads to abnormal $A \beta$ accumulation in the brain and vessels, causing CAA in aged brain. Based on this assumption, several therapeutic interventions have been tried in CAA animal models by enhancing $A \beta$ clearance and drainage systems. For example, experimental gene therapy to up-regulate neprilysin in the brains of aged $\operatorname{Tg} 2576$ mice has been reported to reduce $A \beta$ levels [6]. Promoting perivascular drainage can facilitate $A \beta_{40}$ clearance and improve cognitive deficits in Tg-SwDI mice [7]. Administrating ponezumab, an anti- $A \beta_{40}$ selective antibody, to transgenic mice led to a reduction of $A \beta$ deposition and an improvement of 
vessel function [8]. How to make these basic neuroscience progresses into clinical effective therapies requires more comprehensive understanding of mechanisms involving $A \beta$ clearance under pathological conditions. This review will focus on recent findings of $A \beta$ clearance system and try to discuss the potential interventional targets for future CAA treatment.

\section{Enzyme degradation}

A $\beta$-degrading enzymes including neprilysin, insulindegrading enzymes (IDE), angiotensin-converting enzyme (ACE), cathepsin, etc., play an important role in $\mathrm{A} \beta$ clearance and have a protective role in CAA by reducing the damage of $A \beta$ to vascular smooth muscle cells. A previous review have summarized their crucial role in $\mathrm{AD}$ and CAA, and the up-regulation of cerebral $\mathrm{A} \beta$ degrading enzyme has potential therapeutic effect on $\mathrm{AD}$ [9]. Here we focus on their role in CAA pathology. For example the expression of vascular neprilysin reduced in CAA patients and the decrease was more obvious in Apoe4 carriers [10, 11]. Gene polymorphisms of neprilysin has also been reported to be related to sporadic CAA and disease severity [12]. Both vitro and vivo studies have demonstrated that up-regulation of neprilysin could reduce $A \beta$ concentration and be beneficial to $A D[13,14]$. A recent study suggests that neprilysin activity is suppressed directly or indirectly by dual-specificity tyrosine phosphorylation-regulated kinase 1A (DYRK1A), so DYRK1A inhibition may also be a promising therapeutic target for $\mathrm{AD}$ through up-regulating neprilysin [15]. Another $A \beta$ degrading enzyme IDE isolated from human brain microvessels has been shown to be capable of degrading $A \beta 40$, and the IDE protein levels was increasing in $\mathrm{AD}$ patients with CAA, however its degrading activity was reduced in CAA microvessels [16]. And for ACE, it's has been shown to cleave $A \beta 40$ at the site $\operatorname{Asp}(7)-\operatorname{Ser}(8)$. And the degradation products $A \beta-(1-7)$ and $A \beta-(8-40)$ peptides were less aggregated or cytotoxic [17]. The activity of ACE- 1 was increased in AD patients and in moderate to severe CAA vessel-associated ACE-1 levels were higher [18]. Further study found that ACE variants are related to $\mathrm{ICH}$ recurrence in CAA, possibly by regulating ACE expression [19]. Up-regulation of $A \beta$ degrading enzyme has potential therapeutic effect on $\mathrm{AD}$ and further studies are needed to assess their role in treatment for CAA pathology.

\section{The transcytosis of $A \beta$ across $B B B$}

Blood brain barrier (BBB) refers to plasma and brain barrier composed of cerebral capillary wall and glial cells, as well as a barrier between plasma and cerebral spinal fluid (CSF) composed of choroid plexus named blood-cerebrospinal fluid barrier (BCSFB). BBB can limit the transport of polar molecules into the brain, but the necessary nutrients such as glucose, amino acids, and vitamins can permeate through BBB mediated by receptors on the vascular endothelium. BBB also allows the transport of larger molecules, such as neuroactive peptides and proteins, and plays an important role in the regulation of brain $A \beta$ concentration.

$\mathrm{A} \beta$ can be transported bi-directionally through $\mathrm{BBB}$ by multiple receptors in the vascular endothelium (Fig. 1). Receptors involved transporting peripheral $A \beta$ into the brain consist of advanced glycation end products (RAGE), organic anion transporting polypeptides (OATP) such as Oatp1a4. The receptors mediating $A \beta$ clearance from the brain to the peripheral circulating system include low-density lipoprotein receptor family (LDLR family), ATP-binding cassette transporters (ABC transporters), insulin-sensitive transporter, natriuretic peptide receptor $\mathrm{C}(\mathrm{Npr}-\mathrm{C})$. These receptors regulate the influx and efflux of brain $A \beta$ and maintain the balance of $A \beta$ under normal condition. So any dysfunction of this transportation system can disturb the balance of $A \beta$ distribution and lead to $A \beta$ aggregation in the vessels which contributes to CAA formation in the brain.

\section{Receptors mediating $A \beta$ influx Advanced glycation end products (RAGE)}

RAGE belongs to immunoglobulin receptor superfamilies and can interact with several ligands including soluble $A \beta$. The expression of RAGE was increased in capillary of CAA patients and APP transgenic mice, suggesting the association of RAGE with $A \beta$ aggregation in the capillary [20]. Further study found that in 3xTg-AD transgenic mice, the exogenous pathogenic gene could up-regulate RAGE expression in endothelium cell [21]. RAGE can mediates the transport of $A \beta_{40}$ or $A \beta_{42}$ across BBB into brain, resulting in endothelial cell oxidative stress and expression of proinflammatory cytokines and NF- $\mathrm{kB}$ through redox-dependent activation of RasERK1/2 pathway, p38 MAP (p38), Cdc42/Rac pathway and SAPK/JNK kinase pathways [22], which finally leads to cell apoptosis, inflammatory response and vascular dysfunction. And the inhibition of RAGE-ligand interaction reduces aggregation of $A \beta$ in brain parenchyma in transgenic mouse [23]. Using an in vitro BBB model, Candela et al. [24] found that specific competitive inhibitor against RAGE could decrease the apical-to-basolateral transport of $A \beta_{40}$ and $A \beta_{42}$ significantly, which was a caveolae-dependent process through endothelial cells. And recently, a research observed that 1,25-dihydroxyvitamin D3 $(1,25(\mathrm{OH}) 2 \mathrm{D} 3)$ increased the efflux of $A \beta 40$ from brain to blood through up-regulating LRP1 and downregulating RAGE [25].

Several drugs targeting on RAGE have been tried for treating $\mathrm{AD}$ and CAA. Inhibition of RAGE-ligand 


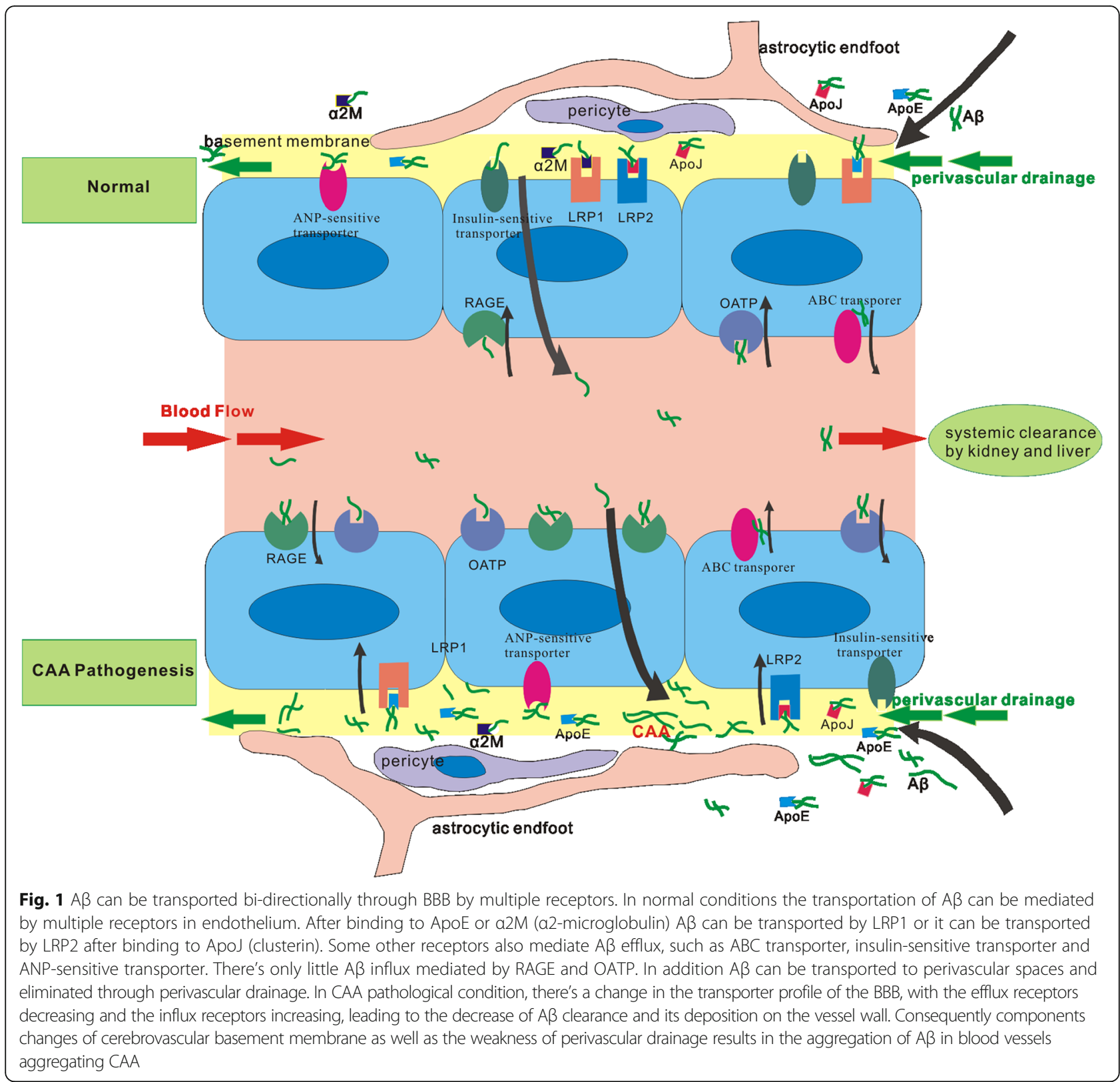

interaction by using soluble RAGE (sRAGE) or antiRAGE antibody can suppress the accumulation of $A \beta$ in brain parenchyma in transgenic mouse models [23, 26]. Specific inhibitor against RAGE can alleviate amyloid deposition as well as improve cognitive function in APP transgenic mouse [27]. TransTech Pharma, Inc. discovered TTP488, which acts as an antagonist of RAGERAGE ligand interaction. Chronic oral dosing of this drug in AD transgenic mouse resulted in a reduction of amyloid deposition in the brain and an improvement of behavioral performance and in phase 2 clinical trial in mild to moderate AD, TTP488 has achieved positive results [28].

\section{Organic anion transporting polypeptides (OATP)}

Members of the OATP family, OATP1A2/SLCO1A2 (Oatp1a4/Slco1a4 in mice) and OATP14 (Oatp14/ Slc21a14 in mice), are expressed on the luminal and abluminal sides of brain capillary endothelial cells. Statins are effective substrates for OATP and the uptake of statins in the liver is mainly dependent on OATP transport. As one kind of the cholesterol reducing drugs, statin has been shown helpful to prevent $\mathrm{AD}$ and the protective effect is probably not only related to their ability to reduce cholesterol levels, but also some other mechanisms may also be involved [29], such as competitively binding OATP with A $\beta$. Do et al. [30] found that 
rosuvastatin and taurocholate, two established Oatp1a4 substrates, decreased $A \beta$ influx, while its inhibitor Lthyroxine increased $A \beta$ influx. So Oatp1a4 might play an important role in the $A \beta$ clearance from brain. More studies are needed to reveal the specific function between Oatp1a4 and $A \beta$, as well as whether its inhibitor Lthyroxine contributes to the $\mathrm{CAA}$ and $\mathrm{AD}$ in pathological process.

\section{Receptors mediate $A \beta$ efflux}

\section{ATP-binding cassette transporters ( $A B C$ transporters)}

$A B C$ transporter is a member of the biggest protein superfamilies, existing in all living organism from microorganism to human. The human $\mathrm{ABC}$ transporter is encoded by 49 genes and is divided into A to G 7 subfamilies based on sequence homology and functional similarity. ABC transporters utilize ATP to provide energy for transport of polar and non-polar molecules across cell membrane, which plays an important role in physiological conditions, and its function defects can lead to serious genetic diseases. The transporters are highly expressed in barrier structure (blood-brain barrier, blood-testis barrier, blood-placental barrier), excretory organs (liver, kidney) and absorption organs (small intestine, colon). Some members of the transporters in $A B C$ transporter subfamilies B, C, G can discharge metabolic wastes, exogenous substances and many drugs from the central nervous system to the blood. Among them the most studied substances include multidrug resistance proteins (MDR1), ATP-binding cassette B1 (ABCB1) or P-glycoprotein (P-gp), multidrug resistanceassociated protein (MRPs), ATP-binding cassette G2 (ABCG2), ATP-binding cassette G1 (ABCG1) or breast cancer resistance protein (BCRP) and ATP-binding cassette G4 (ABCG4). Recent studies have found that ABC transporters are involved in $A \beta$ clearance.

$\mathrm{ABCG} 2$ is highly expressed in CAA and $\mathrm{AD}$ transgenic mouse brain and can inhibit the influx of $A \beta_{40}$ across $\mathrm{BBB}$. In vitro study, inflammatory mediators released by $A \beta$-activated microglia enhance the expression of ABCG2 in vascular endothelial cell [31]. However Carrano et al. [32] observed that the expression of ABCG2 and ABCB1 decreased in capillary of CAA patients, but was not changed in $\mathrm{AD}$ and normal controls. And using a vitro $\mathrm{BBB}$ model, they further found that $A \beta_{42}$ oligomers or coincubating $A \beta_{42}$ with clusterin (apolipoprotein J) downregulated the expression of $\mathrm{ABCB} 1$ in the vascular endothelium without any change of ABCG2, suggesting the special function of $\mathrm{ABCB} 1$ in capillary $\mathrm{CAA}$, and a recent study observed that $A \beta 40$ could mediate the ubiquitination, internalization and proteasome-dependent degradation of $\mathrm{ABCB} 1$ in isolated rat brain capillaries, which indicates that the ubiquitin-proteasome pathway is associated with the lower ABCB1 protein levels in vascular endothelium exposing to $A \beta 40$ [33]. 3xTg$\mathrm{AD}$ transgenic mouse studies demonstrated that the expression of $A \beta$ transporter protein differs in different disease stages. Although the exogenous APP gene can upregulate the expression of influx transporter RAGE and down-regulate the expression of efflux transporter LRP1, mice can counteract this increased net influx by upregulating $A B C G 4 、 A B C G 2 、 A B C B 1$, and maintain the balance of $A \beta$ influx and efflux in $B B B$ [21]. Molecules in CSF including $A \beta$ can also be removed via $A \beta$ transporters at the BCSFB, such as ABCB1, LRP1, LRP2 [34]. During aging, there's a significant alterations in $A \beta$ transporter profile expressed at BCSFB with $A \beta$ efflux transporters increased and $A \beta$ influx transporters decreased $[35,36]$. So BBB and BCSFB is a dynamic barrier, which can adapt to different pathological conditions by changing its transporter profile. More researches are required to elucidate the role of ABCG2 in the pathogenesis of CAA and AD.

\section{Low-density lipoprotein receptor family (LDLR family)}

LDLR family includes at least 10 kinds of receptors, including LDLR, VLDLR, LRP1, LRP1B, LRP2, LRP3, LRP4, LRP5, LRP6 and LRP8. Previous studies revealed that LDLR family was of crucial importance for the development of the nervous system, aging and pathogenesis of $\mathrm{AD}$ [37]. The most well-known function of this receptor family is receptor-mediated endocytosis.

LRP1 expression decreases with aging especially for $\mathrm{AD}$ patients [38]. Along the progression of $\mathrm{AD}$, hypoxia occurs and stimulates the overexpression of the serum response factor (SRF) and myocardin in cerebral vascular smooth muscle cells. SRF and myocardin can further activate sterol regulatory element binding protein-2, which could down-regulate LRP1 [39]. Many LRP1 ligands co-deposite with $A \beta$ in senile plaques and are involved in $A \beta$ clearance (Fig. 1), such as apoE, $\alpha 2$ microglobulin $(\alpha 2 \mathrm{M})$, lactoferrin, urokinase-type plasminogen activator, tissue-type plasminogen activator [40]. Studies have suggested that ApoE4 can block the clearance of soluble $A \beta$ from brain by LRP1 [41], leading to the increasing $A \beta$ deposition in the vascular wall and pathological changes of CAA in APP and ApoE4 double transgenic mice. ApoE4-expressing mice has an elevated ratio of $A \beta 40: 42$ in brain extracellular pools and a lower $A \beta 40: 42$ ratio in CSF, which suggests that ApoE4 leads to the altered transport and clearance of $A \beta$ proteins by LDLR in different brain compartments [42], a possible explanation for the lower $A \beta$ levels in CSF of AD patients with cortical microbleeds [43]. The lipidization level of different ApoE isoforms is not the same. The low lipidization level ApoE4 promotes $A \beta$ deposition, while the higher lipidization level ApoE2 promotes $A \beta$ clearance by LRP1 [44]. While ApoE2 genotype is 
protective for $\mathrm{AD}$, it's related to intracerebral hemorrhage in CAA patients [45].

The cell surface LRP1 has been shown not only related to $A \beta$ cell uptake and the lysosomal degradation of $A \beta$ in vascular smooth muscle cells [46], but also mediating the $A \beta$ efflux through $B B B$ and further elimination by the liver, spleen and kidney [47]. And LRP1 may influence the phagocytosis or macropinocytosis of $A \beta$, because it has been respected to control cytoskeleton architectures through focal adhesion kinase (FAK)/paxillin and/or phosphoinositide 3-kinase (PI3K)/extracellular signal-regulated kinase (ERK) pathways [48, 49]. Recently Steffen E. Storck and colleges developed transgenic mouse models that allow for specific deletion of LRP1 within brain endothelial cells. The selective deletion of brain LRP1 in 5xFAD transgenic mouse can reduce plasma $A \beta$ levels and elevate soluble brain $A \beta$, resulting in aggravated spatial learning and memory deficits [50]. So LRP1 plays an important role in $A \beta$ clearance in $B B B$ via various ligands. Apart from this LRP1 is a multifunctional receptor that can regulate several signaling pathways by binding to other receptors to play a role in the inflammation of atherosclerosis, cancer, and nervous system injury [51]. It can also regulate gene expression through the intracellular domain [49].

LRP2, also named as megalin, is the biggest receptor of the LDLR family, expressed in a variety of absorption epithelial cells such as small intestinal brush border cells and mainly expressed in endothelial cells and choroid plexus in the brain. LRP2 can recognize variety of ligands with different structure and functions including lipoprotein (apoE, clusterin), vitamin-binding proteins, hormones, neurotrophic factors and so on. Many studies have found that LRP2 could faciliate the endocytosis of $A \beta$ as well as its clearance through blood cerebrospinal fluid barrier and blood-brain barrier [46, 52].

After binding of LRP2 to clusterin, the clearance of $A \beta$ by LRP2 in BBB increases, indicating that the interaction between LRP2 and clusterin promotes $A \beta$ efflux (Fig. 1) [53]. Further researchers observed that the efflux of clusterin increased when complexed to $A \beta 40$ in vitro $B B B$ model [54], so clusterin is important for the modulation of $A \beta 40$ transcytosis across the BBB. Carro [55] found that selective deletion of LRP2 in the brain capillary endothelial cells of mice could originate behavioral impairments and neurodegeneration, which were the common clinical manifestations and pathological changes seen in AD brains. However there was no increase in the $A \beta$ laden in the LRP2 deletion model and further studies are required to clarify the role of LRP2 in A $\beta$ clearance. Serum insulin-like growth factor I (IGF-I) is neuroprotective, and in choroid plexus LRP2 can mediate the IGF-I-induced clearance of $A \beta$ and promote the transport of IGF-I into the brain. So LRP2 is able to facilitate
$A \beta$ clearance and inhibit tau phosphorylation or amyloid neurotoxicity through mediating transport of IGF-1 [46].

\section{Other receptors mediated $A \beta$ efflux}

As mentioned above many studies have proved that LRP and P-gp participate in the clearance of $A \beta$, however some researchers found that these two receptors do not play a major role in $A \beta_{40}$ clearance by BBB. [56] So there must be other molecules involved in $A \beta_{40}$ transport through BBB. It has been found that insulin can significantly inhibit [125I] $A \beta_{40}$ through BBB in rats, whereas insulin receptor-specific inhibitors cannot block the elimination of [125I] $A \beta_{40}$ across BBB into blood, [57] which suggests that there are unknown insulin-sensitive receptors involved in the elimination of [125I] $\mathrm{A} \beta_{40}$.

Natriuretic peptide receptor $\mathrm{C}(\mathrm{Npr}-\mathrm{C})$, expressed in the brain capillary endothelium, can mediate the elimination of atrial natriuretic peptide (ANP) across BBB. Ito [58] found that ANP elimination can be inhibited by $\mathrm{A} \beta_{40}$, however, there was no direct interaction between Npr-C and $A \beta_{40}$, indicating that the clearance of $A \beta_{40}$ may be facilitated by other ANP-sensitive receptor expressed in cerebrovascular endothelium. Meanwhile in vitro study they found that insulin-degrading enzyme was involved in $A \beta_{40}$ clearance through insulin-sensitive transporter and ANP-sensitive receptor in addition to the direct degradation of the protein. As a result, high ANP level caused by cardio-cerebrovascular disease in the brain may suppress the transport of $A \beta$ across $B B B$ to some extent, which could aggravate $A \beta$-induced pathological changes. However the structure and the function of these receptors are not clear and more studies are required to elucidate their role in blood brain barrier and $A \beta$ clearance.

\section{Interstitial fluid bulk-flow clearance Perivascular drainage}

After released from the neuron, $A \beta_{42}$ tends to aggregate and form parenchyma senile plaques, but $A \beta_{40}$ is resistant to aggregation in parenchyma and can be removed through the drainage of interstitial fluid along the cerebral capillaries and arteries (Fig. 2), where part of the protein can be eliminated through BBB (Figure 1). Any dysfunction in this process can trigger or promote the accumulation of $A \beta_{40}$ in the vascular basement membrane leading to CAA pathological changes [59].

\section{Vascular basement membrane}

Vascular basement membrane is a special extracellular matrix of the endothelial basal surface, mainly secreted by endothelial cells. The main components include type IV collagen, laminin, nestin, heparan sulfate proteoglycan and other molecules. Cerebrovascular basement membrane plays a key role in vascular development, 


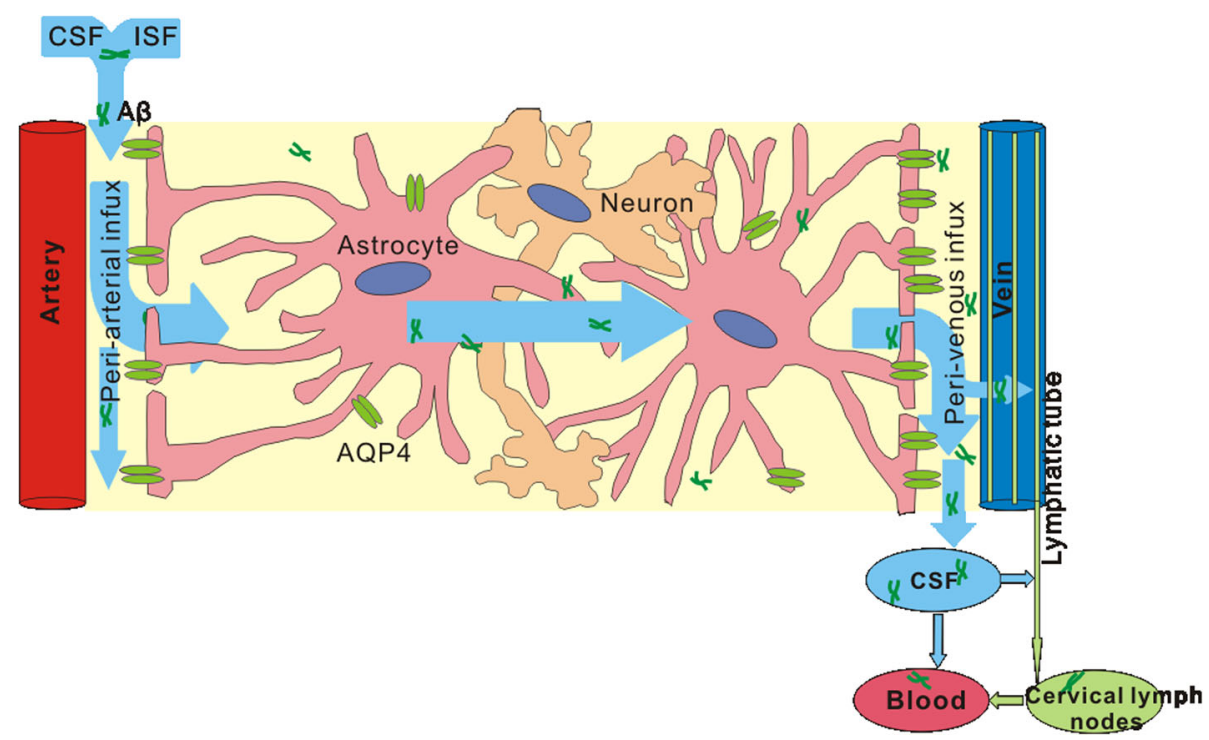

Fig. 2 Brain glymphatic pathway facilitates the drainage of excess Aß in CSF and ISF. CSF can flows into perivascular space through Virchow-Robin space, and then enters into brain parenchyma mixing with extracellular ISF. The CSF and ISF can travel along the arterial and capillary membrane then flow into leptomeningeal blood vessels or subarachnoid space, or move to cervical lymphnodes by lymphatic drainage and finally flow into blood. The higher expression of AQP4 surrounding veins provides an arteriovenous hydrostatic gradient to drive glymphatic drainage

formation, BBB maintenance, and migration of peripheral cells including leukocytes [60]. There is continuity between brain extracellular matrix and cerebral capillary basement membrane (Fig. 1). So it is possible that interstitial fluid may be drained through the perivascular pathway to the peripheral which includes $A \beta$.

Increased age-related risk factors for cerebrovascular, such as arteriosclerosis, are also the risk factors for CAA and AD. Further study found that cerebrovascular basement membrane thickening, vacuolization, reduplication appeared in the elderly and the old mouse, were more predominant in the AD brain [61]. As to the workforce of the drainage system, it has been found that the drainage is only present in the live animals and it would stop when there is a cardiac arrest. So it is the blood flow that provides the main impetus for perivascular drainage [62]. After each heart beat the blood vessel will produce a reverse wave with the opposite direction of the blood flow, which appears to facilitate fluid and solute transport in perivascular drainage [63]. As a result, agerelated cerebrovascular sclerosis, fibrosis, and loss of smooth muscle cells may reduce the artery contractile force, which leads to the weakness of the perivascular drainage and then induces the impairment of $A \beta$ clearance and increases CAA risk.

\section{Components' changes of cerebrovascular basement membrane}

CAA transgenic mouse show a significant reduction in type IV collagen, laminin, nidogen and an obvious increase in heparan sulfate proteoglycan compared to wild type mouse. More importantly the morphological and functional effects of aging on cerebral basement membranes and perivascular drainage differ between brain regions, with a more obvious influence on hippocampus [61]. As a risk factor for sporadic AD and CAA, ApoE4 has been shown to interfere with perivascular drainage of soluble $A \beta$, which may be achieved by the alteration of protein expression in the vascular basement membrane [64].

\section{The role of apolipoprotein in perivascular drainage}

ApoE protein in the cerebral vascular wall increased after anti-amyloid $\beta$ immunotherapy [65], and study has suggested the co-localization of ApoE and $A \beta$ in the perivascular drainage route (Fig. 1) [66]. After intraventricular injection of $A \beta_{40}$ in ApoE transgenic mice, researchers found the co-deposition of ApoE4 and $A \beta_{40}$ in the vessel wall rather than ApoE3 [64], indicating that the drainage rate of $A \beta 40$ mediated by ApoE4 is much slower. Probably because the binding force between ApoE4-A $\beta$ complex and basement membrane laminin is much weaker than that of ApoE3-A $\beta$ complex, which suggests the impaired clearance of ApoE4-A $\beta$ complex through perivascular drain compared to other ApoE-A $\beta$ complexes [67]. ApoE4 has lower antioxidant activity than other ApoE isoforms [68] thus accelerate the loss of vascular integrity, breakdown of BBB which contributes to CAA. Another apolipoprotein clusterin was found to have high immunoreactivity in the arterioles and capillaries of $\mathrm{AD}$ and CAA patients, indicating clusterin is more likely to co-locate with $A \beta 40$ rather than 
A $\beta 42$ [69], so that clusterin might mediate the elimination of $A \beta 40$ through perivascular drainage pathway.

\section{Association between brain parenchymal and cerebrovascular $A \beta$ deposition}

Passive immunotherapy against $\mathrm{A} \beta$ in $\mathrm{AD}$ mice model and human has been confirmed to reduce amyloid deposition but it aggravates CAA pathological lesions [70]. $A \beta$ deposition on the cerebral vessels flowing passive immunotherapy contains more $A \beta_{42}$, which suggests that the parenchymal insoluble $A \beta$ can be transformed into soluble form by specific antibody and then transported into the vascular basement membrane, and the failure of periarterial drainage aggregates CAA in AD patients.

Diem et al. established a computational model to investigate the $A \beta$ periarterial drainage in the context of diffusion in the brain, and their studies showed that periarterial drainage of $A \beta$ along basal membranes was more rapid compared with diffusion [71]. These results demonstrate that periarterial drainage is involved in the pathogenesis of CAA and $\mathrm{AD}$ as well as immunotherapy related complications. Meanwhile this indicates, to some extent, that normal cerebrovascular function is critical to the success of AD immunotherapy. For example, vasoactive drug cilostazol, a selective inhibitor of phosphodiesterase (PDE) III, has recently shown to significantly improve cognitive decline in patients with mild cognitive impairment [72]. Further animal study revealed that cilostazol reduced $A \beta_{40}$ deposits and rescued cognitive decline in $\mathrm{Tg}$-SwDI mice by promoting perivascular drainage of soluble $A \beta_{40}$ [7].

Therefore, the composition, protein expression and morphology changes of the cerebrovascular basement membrane can impair the perivascular drainage of $A \beta$, and the deposition of $A \beta$ on the vessel wall can further aggravating $A \beta$ drainage obstacles. This vicious cycle may be an important precipating factor for CAA pathology. Understanding the dynamics of perivascular drainage of the brain will help to find new therapeutic intervention for CAA and AD.

\section{Glymphatic pathways}

The glymphatic system is named based on its functional similarity to the peripheral lymphatic system, acting as a convective flux of CSF and ISF in the brain and strictly dependent on water channel aquaporin-4 (AQP4) expressed on the perivascular astrocytic endfeet [73]. Using in vivo two-photon microscopy in mice the dynamics of the glymphatic pathway was described for the first time. ISF solutes diffuse and finally enter the capillary and arterial basement membrane [74], then flow to the leptomeningeal blood vessels at the surface of the brain and finally move to cervical lymph nodes. CSF can flow into perivascular drainage route through Virchow-Robin space, and then enter into brain parenchyma mixing with extracellular ISF (Fig. 2) [75]. The perivascular drainage pathway was considered to be the lymphatic drainage in the brain, and it's still unclear whether these two pathways are distinct pathways or perhaps they just reflect the same transport pathway under different physiological or experimental conditions [36].

Recent animal studies found that AQP4-dependent glymphatic pathway played an important role in promoting clearance of soluble $A \beta$ from CSF and extracellular fluid. In mouse lacking AQP4 in astrocytes, the $A \beta$ clearance was reduced by $55-65 \%$ compared with wild mouse. And the expression of AQP4 surrounding veins is higher than arterial, perhaps providing an arteriovenous hydrostatic gradient in order to drive perivascular CSF and ISF bulk flow [76]. In aging mouse brain loss of perivascular AQP4 results in impairment of perivascular CSF recirculation and $A \beta$ clearance [77]. And deletion of AQP4 in AD transgenic mice aggregates brain $A \beta$ accumulation and memory impairment [78]. In postmortem human tissue studies AQP4 was shown to be abnormally expressed in AD and CAA brains [79], and loss of perivascular AQP4 localization was associated with AD status [80]. This is intriguing, for reason that $\mathrm{AD}$ is associated with reactive gliosis. We speculate that altered AQP4 expression and depolarization in perivascular astrocytic endfeet under neuropathological conditions may be a triggering factor that contribute to impaired interstitial bulk flow and renders the aging brain more vulnerable to $A \beta$ accumulation in vessel walls. That needs more studies to clarify the internal mechanism.

Following the clearance of free $\mathrm{A} \beta$ from the brain ISF into CSF sink via bulk flow, the proteins must be removed into the circulation or possibly through the meningeal lymphatics into the lymphatic system (Fig. 2) [81]. In peripheral organs ISF drains from tissues to lymph nodes. Previously it was thought that the central nervous system (CNS) lacked lymphatic vessels. A recent study has discovered the meningeal lymphatic vessels which expressed the specific molecular markers of lymphatic endothelial cells and are able to drain CSF and ISF into the deep cervical lymph nodes [81]. So after the clearance of $A \beta$ through ISF-to-CSF bulk flow these meningeal lymphatic vessels may provide a conventional path for its further elimination to the peripheral. As discussed above, cilostazol can improve cognitive function of MCI patients [82] and the protective effect is probably not only related to its antiplatelet and vasodilator ability, we suspect that its ability to improve lymphatic function [83] may also be involved, although this hypothesis needs further studies to improve. 


\section{Complement-related clearance system}

Brain inflammation commonly occurs in CAA and AD, in which the accumulation of $A \beta$ in the arterioles and capillaries of CAA patients might activate the complement system. The activated complement components, as a consequence, can produce a chronic, cumulating and low-level inflammatory response during disease course [84]. A $\beta$ binding to C1q can activate complement system by classical pathway or by alternative pathway without C1q [85] (Fig. 3). These complement components are mainly expressed by neuron, microglial, astrocyte and cerebral microvascular endothelial cells (CMEC). Further study showed that complement proteins can also be produced by cerebrovascular smooth muscle cells and their activation aggravates vascular damage [86]. A recent study revealed that $\mathrm{C} 3$ secreted by astrocyte can interact with $\mathrm{C} 3 \mathrm{aR}$ in microglial, mediating the inflammatory response induced by $A \beta$ in central nervous system. $A \beta$ can up-regulate the expression of NF- $\mathrm{KB}$ in astrocyte and promote the complement activation. Moreover, $A \beta$ attenuated phagocytosis opsonized by complement and resulted in cognitive decline and $A \beta$ deposition. C3aR antagonist can improve glial cell hyperplasia and $A \beta$ deposition, exerting a therapeutic effect on the chronic inflammation of the nervous system [87]. However brain $A \beta$ deposition increased when the activation of $\mathrm{C} 3$ was inhibited by expressing soluble complement receptor- related protein y (sCrry) in human amyloid precursor (hAPP) transgenic mice [88]. Complement activation components bind to $A \beta$-induced apoptotic cell surface, and the microglia complement receptors are implicated in their clearance [89]. So certain inflammatory response in the brain appears to be favorable to neurodegenerative disease.

$\mathrm{CR} 1$, also known as CD35 or $\mathrm{C} 3 \mathrm{~b} / \mathrm{C}$, is an impotent protein in the complement regulatory system, which can enhance the endocytosis of C3b, C4b, C1q coated particles by phagocytic cells and regulate complement activation by inhibiting $\mathrm{C} 3$ and $\mathrm{C} 5$ invertase activity. Immune complexes, aberrant antibodies or $\mathrm{A} \beta$ can be transported by erythrocyte CR1 receptors to the liver for removal. Rogers found that $A \beta$ can be cleared from the bloodstream by CR1 receptors on erythrocyte after binding to C3b (Fig. 3) [90]. In addition, $\mathrm{AD}$ and $\mathrm{MCI}$ patients show lower levels of $C 3$-opsonized erythrocyte $A \beta$ compared to cognitive normal subjects. So CR1 may be involved in $A \beta$ metabolism and the dysfunction of $C 3 \mathrm{~b}$ dependent $A \beta$ adherence to $C R 1$ can increase the risk of AD. However, it remained unclear how this additional C3b binding site of CR1 exerts its risk for CAA and AD.

In recent years, genome-wide association mapping studies (GWAS) have provided strong evidence for CR1 single nucleotide polymorphism (SNP) being a risk factor for sporadic AD, in which SNP rs6656401 was positively correlated with $A \beta$ deposition in brain $[91,92,93]$. Given the overlap of CAA and AD pathological features, Biffi investigated whether this variant is also correlated with CAA risk and its pathological changes [94]. They found that rs6656401 aggravated CAA-related intracerebral hemorrhage $(\mathrm{ICH})$, risk of recurrent $\mathrm{CAA}-\mathrm{ICH}$, as

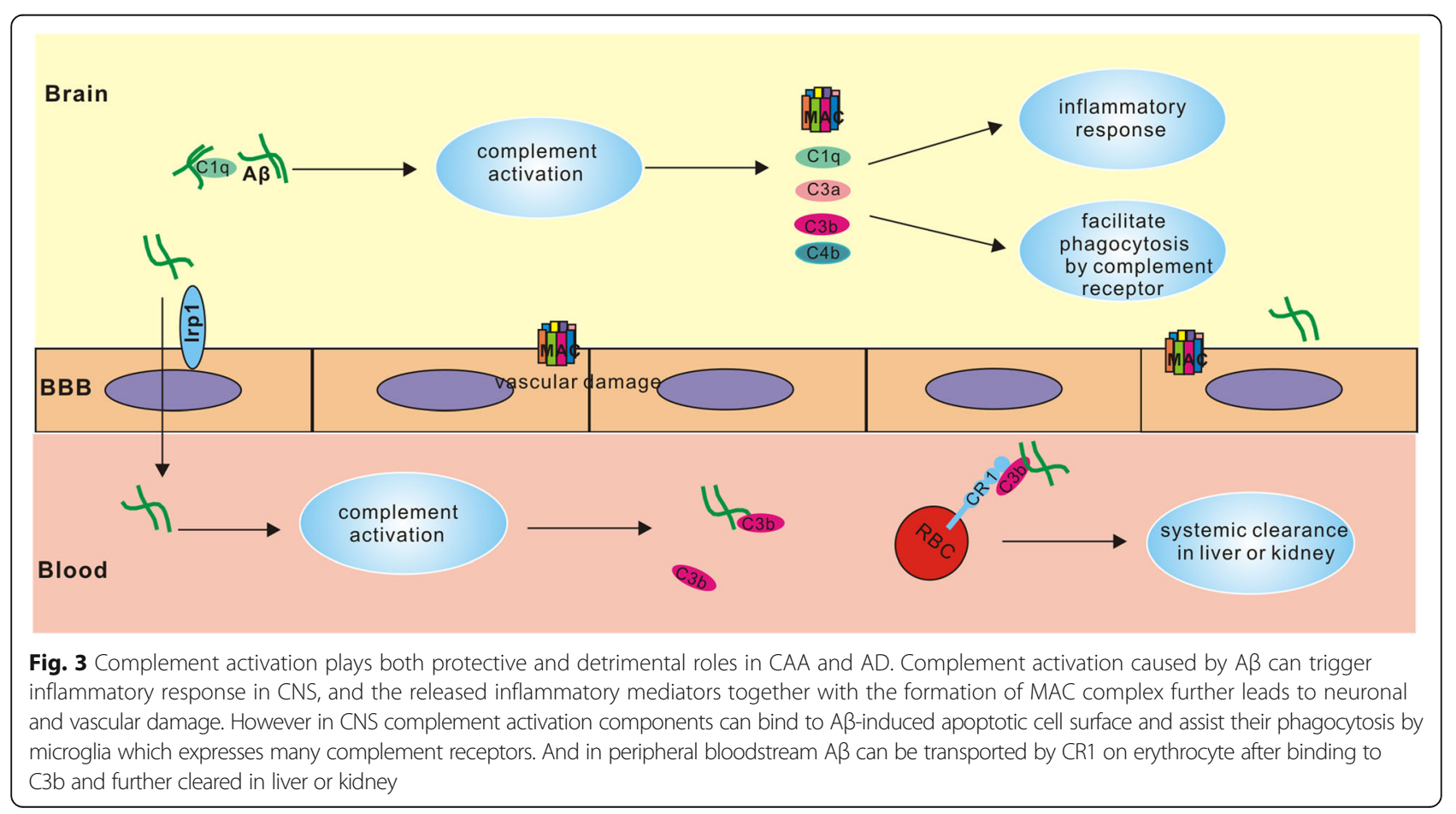


well as cerebrovascular $A \beta$ deposition. So complement system may be an evoking factor for the pathogenesis of $\mathrm{AD}$ and CAA, not just being activated as a result of $\mathrm{A} \beta$ deposition. Rs6656401 is located on the non-coding region of CR1 gene and CR1 gene containing this SNP encodes CR1 protein with additional C3b binding sites [95]. It is possible that these additional C3b binding sites of CR1 increase the ability of CR1 to carry more $A \beta$ for liver to degradation.

The only SNP found in the coding region of CR1 gene so far is rs4844609 which encodes a domain that binds to mannan-binding lectin (MBL) and fibronectin [96]. MBL are found to bind to $A \beta$ [97], however the relationship between MBL and AD as well as CAA is unknown. Since $C 1 q, C 4 b$, and $C 3 b$ are associated with $A \beta$ plaques, it is speculated that rs4844609 and rs665401 may influence the affinity of CR1 with $\mathrm{C} 1 \mathrm{q}, \mathrm{C} 4 \mathrm{~b}$, and $\mathrm{C} 3 \mathrm{~b}$ by altering the molecular structure of the receptor and further affect the clearance of A $\beta$. Rs4844609 can also regulate the cleavage site of the CR1 protein to produce soluble CR1 (sCR1) [98]. sCR1 could regulate complement activation on cell surface and may affect the removal of immune complex and $A \beta$. A recent study revealed that there is a slight difference in sCR1 levels among populations with different CR1 genotype, and CR1 has a better affinity for C1q and C3b in people with rs4844609, but these differences are not associated with changes in cognitive function [99]. Additionally, it's unknown whether different CR1 isoforms can influence the clearance of peripheral $A \beta$. So more precise methods are needed to determine the affinity of different CR1 isoforms with $\mathrm{C} 1 \mathrm{q}, \mathrm{C} 3 \mathrm{~b}$ and to identity the molecular pathways of these polymorphisms as related to $A D$ or CAA susceptibility.

\section{Conclusions}

The aggregation of $A \beta$ in the brain increases with aging, so age-related risk factors are also associated with impaired $A \beta$ metabolism. As a result the incidence of $\mathrm{CAA}$ and $\mathrm{AD}$ significantly increases in the aging population, bringing great burden to society and their families. The deposition of $A \beta$ on the vessel wall can induce the release of inflammatory factors, complement activation, oxidative stress, which further lead to the damage of vascular endothelium and smooth muscle cells resulting in intracerebral hemorrhage, ischemic stroke as well as cognitive decline. However, until now there's no effective way to prevent or reverse CAA pathological changes and the clearance of $A \beta$ is regulated by variable factors and many of them are still unclear. So identification of molecular pathways involved in $A \beta$ clearance will provide new targets for $\mathrm{AD}$ and CAA therapeutic intervention.

\section{Abbreviations}

ABC: ATP-binding cassette; AD: Alzheimer's disease; ANP: Atrial natriuretic peptide; APP: Amyloid precursor; AB: Amyloid $\beta$-protein; BBB: Blood brain barrier; BCRP: Breast cancer resistance protein; BCSFB: Blood-cerebrospinal fluid barrier; CAA: Cerebral amyloid angiopathy; CEMC: Cerebral microvascular endothelial cell; Crry: Complement receptor- related protein y; CSF: cerebral spinal fluid; ET-1: Endothelin-1; GWAS: Genome-wide association mapping studies;

ICH: Intracerebral hemorrhage; IDE: Insulin-degrading enzyme; ISF: Interstitial fluid; LDLR: Low-density lipoprotein receptor; MBL: Mannan-binding lectin;

MDR1: Multidrug resistance proteins; MRPs: Multidrug resistance-associated protein; Npr-C: Natriuretic peptide receptor; OATP: Organic anion transporting polypeptides; PDE: Phosphodiesterase; P-gp: P-glycoprotein; RAGE: Advanced glycation end products; SRF: Serum response factor; a2M: a2-microglobulin

\section{Acknowledgements}

Not applicable.

Funding

This work was supported by national natural science grant (81570035).

\section{Availability of data and materials}

Data sharing not applicable to this article as no datasets were generated or analyzed during the current study.

\section{Authors' contributions}

XMQ drafted the manuscript. JFM revised the manuscript. Both authors read and approved the final manuscript.

Ethics approval and consent to participate

Not applicable.

\section{Consent for publication}

Not applicable.

\section{Competing interests}

The authors declare that they have no competing interests.

Received: 3 March 2017 Accepted: 1 August 2017

Published online: 17 August 2017

\section{References}

1. Biffi A, Halpin A, Towfighi A, Gilson A, Busl K, Rost N, et al. Aspirin and recurrent intracerebral hemorrhage in cerebral amyloid angiopathy. Neurology. 2010;75:693-8.

2. Boyle PA, Yu L, Nag S, Leurgans S, Wilson RS, Bennett DA, et al. Cerebral amyloid angiopathy and cognitive outcomes in community-based older persons. Neurology. 2015;85:1930-6.

3. Scolding NJ, Joseph F, Kirby PA, Mazanti I, Gray F, Mikol J, et al. Abetarelated angiitis: primary angiitis of the central nervous system associated with cerebral amyloid angiopathy. Brain. 2005;128:500-15.

4. Jellinger KA. Alzheimer disease and cerebrovascular pathology: an update. J Neural Transm. 2002;109:813-36.

5. Yamada M. Cerebral amyloid angiopathy: emerging concepts. J Stroke. 2015;17:17-30.

6. Iwata N, Mizukami H, Shirotani K, Takaki Y, Muramatsu S, Lu B, et al. Presynaptic localization of neprilysin contributes to efficient clearance of amyloid-beta peptide in mouse brain. J Neurosci. 2004;24:991-8.

7. Maki T, Okamoto Y, Carare RO, Hase Y, Hattori Y, Hawkes CA, et al. Phosphodiesterase iii inhibitor promotes drainage of cerebrovascular beta-amyloid. Ann Clin Transpl Neurol. 2014;1:519-33.

8. Bales KR, O'Neill SM, Pozdnyakov N, Pan F, Caouette D, Pi Y, et al. Passive immunotherapy targeting amyloid-beta reduces cerebral amyloid angiopathy and improves vascular reactivity. Brain. 2016;139:563-77.

9. Saito S, Ihara M. New therapeutic approaches for alzheimer's disease and cerebral amyloid angiopathy. Frontiers Aging Neuroscience. 2014;6:290

10. Carpentier M, Robitaille Y, DesGroseillers L, Boileau G, Marcinkiewicz M. Declining expression of neprilysin in alzheimer disease vasculature: possible involvement in cerebral amyloid angiopathy. J Neuropathol Exp Neurol. 2002;61:849-56. 
11. Miners JS, Van Helmond Z, Chalmers K, Wilcock G, Love S, Kehoe PG. Decreased expression and activity of neprilysin in alzheimer disease are associated with cerebral amyloid angiopathy. J Neuropathol Exp Neurol. 2006;65:1012-21.

12. Yamada M. Cerebral amyloid angiopathy and gene polymorphisms. J Neurol Sci. 2004;226:41-4.

13. Lim CS, Alkon DL. Pkcepsilon promotes hud-mediated neprilysin mrna stability and enhances neprilysin-induced abeta degradation in brain neurons. PLoS One. 2014;9:e97756.

14. Iwata N, Sekiguchi M, Hattori Y, Takahashi A, Asai M, Ji B, et al. Global brain delivery of neprilysin gene by intravascular administration of aav vector in mice. Sci Rep. 2013;3:1472.

15. Kawakubo T, Mori R, Shirotani K, Iwata N, Asai M. Neprilysin is suppressed by dual-specificity tyrosine-phosphorylation regulated kinase 1a (dyrk1a) in down-syndrome-derived fibroblasts. Biol Pharm Bull. 2017;40:327-33.

16. Morelli L, Llovera RE, Mathov I, Lue LF, Frangione B, Ghiso J, et al. Insulindegrading enzyme in brain microvessels: proteolysis of amyloid \{beta\} vasculotropic variants and reduced activity in cerebral amyloid angiopathy J Biol Chem. 2004;279:56004-13.

17. Hu J, Igarashi A, Kamata M, Nakagawa H. Angiotensin-converting enzyme degrades alzheimer amyloid beta-peptide (a beta); retards a beta aggregation, deposition, fibril formation; and inhibits cytotoxicity. J Biol Chem. 2001;276:47863-8.

18. Miners JS, Ashby E, Van Helmond Z, Chalmers KA, Palmer LE, Love S, et al. Angiotensin-converting enzyme (ace) levels and activity in alzheimer's disease, and relationship of perivascular ace-1 to cerebral amyloid angiopathy. Neuropathol Appl Neurobiol. 2008;34:181-93.

19. Domingues-Montanari S, Hernandez-Guillamon M, Fernandez-Cadenas I, Mendioroz M, Boada M, Munuera J, et al. Ace variants and risk of intracerebral hemorrhage recurrence in amyloid angiopathy. Neurobiol Aging. 2011;32(551):e513-22.

20. Carrano A, Hoozemans JJ, van der Vies SM, Rozemuller AJ, van Horssen J, de Vries HE. Amyloid beta induces oxidative stress-mediated blood-brain barrier changes in capillary amyloid angiopathy. Antioxid Redox Signal. 2011;15:1167-78.

21. Do TM, Dodacki A, Alata W, Calon F, Nicolic S, Scherrmann JM, et al. Agedependent regulation of the blood-brain barrier influx/efflux equilibrium of amyloid-beta peptide in a mouse model of alzheimer's disease (3xtg-ad). J Alzheimers Dis. 2015;49:287-300.

22. Origlia N, Arancio O, Domenici L, Yan SS. Mapk, beta-amyloid and synaptic dysfunction: the role of rage. Expert Rev. Neurother. 2009;9:1635-45.

23. Deane R, Du Yan S, Submamaryan RK, LaRue B, Jovanovic S, Hogg E, et al. Rage mediates amyloid-beta peptide transport across the blood-brain barrier and accumulation in brain. Nature Med. 2003;9:907-13.

24. Candela P, Gosselet F, Saint-Pol J, Sevin E, Boucau MC, Boulanger E, et al. Apical-to-basolateral transport of amyloid-beta peptides through bloodbrain barrier cells is mediated by the receptor for advanced glycation end-products and is restricted by p-glycoprotein. J Alzheimers Dis. 2010; 22:849-59.

25. Guo YX, He LY, Zhang M, Wang F, Liu F, Peng WX. 1,25-dihydroxyvitamin d3 regulates expression of Irp1 and rage in vitro and in vivo, enhancing abeta1-40 brain-to-blood efflux and peripheral uptake transport. Neuroscience. 2016;322:28-38.

26. Rocken C, Kientsch-Engel R, Mansfeld S, Stix B, Stubenrauch K, Weigle B, et al. Advanced glycation end products and receptor for advanced glycation end products in aa amyloidosis. Am J Pathol. 2003;162:1213-20.

27. Deane R, Singh I, Sagare AP, Bell RD, Ross NT, LaRue B, et al. A multimodal rage-specific inhibitor reduces amyloid beta-mediated brain disorder in a mouse model of alzheimer disease. J Clin Invest. 2012;122:1377-92.

28. Burstein AH, Grimes I, Galasko DR, Aisen PS, Sabbagh M, Mjalli AM. Effect of ttp488 in patients with mild to moderate alzheimer's disease. BMC Neurol. 2014;14:12.

29. Shinohara M, Sato N, Kurinami H, Takeuchi D, Takeda S, Shimamura M, et al. Reduction of brain beta-amyloid (abeta) by fluvastatin, a hydroxymethylglutaryl-coa reductase inhibitor, through increase in degradation of amyloid precursor protein c-terminal fragments (app-ctfs) and abeta clearance. J Biol Chem. 2010;285:22091-102.

30. Do TM, Bedussi B, Chasseigneaux S, Dodacki A, Yapo C, Chacun H, et al. Oatp1a4 and an I-thyroxine-sensitive transporter mediate the mouse blood-brain barrier transport of amyloid-beta peptide. J Alzheimers Dis. 2013;36:555-61.
31. Xiong H, Callaghan D, Jones A, Bai J, Rasquinha I, Smith C, et al. Abcg2 is upregulated in alzheimer's brain with cerebral amyloid angiopathy and may act as a gatekeeper at the blood-brain barrier for abeta (1-40) peptides. J Neuroradiol. 2009;29:5463-75.

32. Carrano A, Snkhchyan H, Kooij G, van der Pol S, van Horssen J, Veerhuis R, et al. Atp-binding cassette transporters p-glycoprotein and breast cancer related protein are reduced in capillary cerebral amyloid angiopathy. Neurobiol Aging. 2014;35:565-75.

33. Hartz AM, Zhong Y. Abeta40 reduces p-glycoprotein at the blood-brain barrier through the ubiquitin-proteasome pathway. J Neurosci. 2016;36: 1930-41.

34. Erickson MA, Banks WA. Blood-brain barrier dysfunction as a cause and consequence of alzheimer's disease. J Cereb Blood Flow Metab. 2013;33: 1500-13.

35. Pascale CL, Miller MC, Chiu C, Boylan M, Caralopoulos IN, Gonzalez L, et al. Amyloid-beta transporter expression at the blood-csf barrier is agedependent. Fluids Barriers CNS. 2011;8:21.

36. Tarasoff-Conway JM, Carare RO, Osorio RS, Glodzik L, Butler T, Fieremans E, et al. Clearance systems in the brain-implications for alzheimer disease. Nat Rev. Neurol. 2015;11:457-70.

37. Auderset $L$, Landowski LM, Foa L. Low density lipoprotein receptor related proteins as regulators of neural stem and progenitor cell function. Stem Cells Int. 2016;2016:2108495.

38. Kang DE, Pietrzik CU, Baum L, Chevallier N, Merriam DE, Kounnas MZ, et al. Modulation of amyloid beta-protein clearance and alzheimer's disease susceptibility by the Idl receptor-related protein pathway. J Clin Invest. 2000;106:1159-66.

39. Bell RD, Deane R, Chow N, Long X, Sagare A, Singh I, et al. Srf and myocardin regulate Irp-mediated amyloid-beta clearance in brain vascular cells. Nat Cell Biol. 2009;11:143-53.

40. Rebeck GW, Harr SD, Strickland DK, Hyman BT. Multiple, diverse senile plaque-associated proteins are ligands of an apolipoprotein e receptor, the alpha 2-macroglobulin receptor/low-density-lipoprotein receptor-related protein. Ann Neurol. 1995;37:211-7.

41. Deane R, Sagare A, Hamm K, Parisi M, Lane S, Finn MB, et al. Apoe isoformspecific disruption of amyloid beta peptide clearance from mouse brain. J Clin Investig. 2008;118:4002-13.

42. Fryer JD, Simmons K, Parsadanian M, Bales KR, Paul SM, Sullivan PM, et al. Human apolipoprotein e4 alters the amyloid-beta 40:42 ratio and promotes the formation of cerebral amyloid angiopathy in an amyloid precursor protein transgenic model. J Neurosci. 2005;25:2803-10.

43. Noguchi-Shinohara M, Komatsu J, Samuraki M, Matsunari I, Ikeda T, Sakai K, et al. Cerebral amyloid angiopathy-related microbleeds and cerebrospinal fluid biomarkers in alzheimer's disease. J Alzheimers Dis. 2017:55(3):905-13.

44. Hu J, Liu CC, Chen XF, Zhang YW, Xu H, Bu G. Opposing effects of viral mediated brain expression of apolipoprotein e2 (apoe2) and apoe4 on apoe lipidation and abeta metabolism in apoe4-targeted replacement mice. Mol Neurodegener. 2015;10:6.

45. Charidimou A, Martinez-Ramirez S, Shoamanesh A, Oliveira-Filho J, Frosch M, Vashkevich A, et al. Cerebral amyloid angiopathy with and without hemorrhage: evidence for different disease phenotypes. Neurology. 2015;84:1206-12.

46. Carro E, Spuch C, Trejo JL, Antequera D, Torres-Aleman I. Choroid plexus megalin is involved in neuroprotection by serum insulin-like growth factor i. J Neuroradiol. 2005;25:10884-93.

47. Shibata M, Yamada S, Kumar SR, Calero M, Bading J, Frangione B, et al. Clearance of alzheimer's amyloid-ss (1-40) peptide from brain by ldl receptor-related protein-1 at the blood-brain barrier. J Clin Investig. 2000;106:1489-99.

48. Dedieu S, Langlois B. Lrp-1: a new modulator of cytoskeleton dynamics and adhesive complex turnover in cancer cells. Cell Adhes Migr. 2008;2:77-80.

49. Kanekiyo T, Bu G. The low-density lipoprotein receptor-related protein 1 and amyloid-beta clearance in alzheimer's disease. Front Aging Neurosci. 2014;6:93.

50. Storck SE, Meister S, Nahrath J, Meissner JN, Schubert N, Di Spiezio A, et al. Endothelial Irp1 transports amyloid-beta1-42 across the blood-brain barrier. I Clin Invest. 2016;126:123-36.

51. Gonias SL, Campana WM. Ldl receptor-related protein-1: a regulator of inflammation in atherosclerosis, cancer, and injury to the nervous system. Am J Pathol. 2014;184:18-27. 
52. Deane R, Wu Z, Sagare A, Davis J, Du Yan S, Hamm K, et al. Lrp/amyloid beta-peptide interaction mediates differential brain efflux of abeta isoforms. Neuron. 2004;43:333-44.

53. Bell RD, Sagare AP, Friedman AE, Bedi GS, Holtzman DM, Deane R, et al. Transport pathways for clearance of human alzheimer's amyloid betapeptide and apolipoproteins e and $\mathrm{j}$ in the mouse central nervous system. J Cereb Blood Flow Metab. 2007;27:909-18.

54. Merino-Zamorano C, Fernandez-de Retana S, Montanola A, Batlle A, SaintPol J, Mysiorek C, et al. Modulation of amyloid-beta1-40 transport by apoa and apoj across an in vitro model of the blood-brain barrier. J Alzheimers Dis. 2016;53:677-91.

55. Dietrich M, Antequera D, Pascual C, Castro N, Bolos M, Carro E. Alzheimer's disease-like impaired cognition in endothelial-specific megalin-null mice. J Alzheimers Dis. 2014;39:711-7.

56. Ito S, Ueno T, Ohtsuki S, Terasaki T. Lack of brain-to-blood efflux transport activity of low-density lipoprotein receptor-related protein-1 (Irp-1) for amyloid-beta peptide (1-40) in mouse: involvement of an Irp-1-independent pathway. J Neurochem. 2010;113:1356-63.

57. Shiiki T, Ohtsuki S, Kurihara A, Naganuma H, Nishimura K, Tachikawa M, et al. Brain insulin impairs amyloid-beta (1-40) clearance from the brain. J Neurosci. 2004:24:9632-7.

58. Ito S, Ohtsuki S, Murata S, Katsukura Y, Suzuki H, Funaki M, et al. Involvement of insulin-degrading enzyme in insulin- and atrial natriuretic peptide-sensitive internalization of amyloid-beta peptide in mouse brain capillary endothelial cells. J Alzheimers Dis. 2014;38:185-200.

59. Weller RO, Massey A, Newman TA, Hutchings M, Kuo YM, Roher AE. Cerebral amyloid angiopathy: Amyloid beta accumulates in putative interstitial fluid drainage pathways in alzheimer's disease. Am J Pathol. 1998;153:725-33.

60. Wu C, Ivars F, Anderson P, Hallmann R, Vestweber D, Nilsson P, et al. Endothelial basement membrane laminin alpha5 selectively inhibits $t$ lymphocyte extravasation into the brain. Nature Med. 2009;15:519-27.

61. Hawkes CA, Gatherer M, Sharp MM, Dorr A, Yuen HM, Kalaria R, et al. Regional differences in the morphological and functional effects of aging on cerebral basement membranes and perivascular drainage of amyloidbeta from the mouse brain. Aging Cell. 2013;12:224-36.

62. Ball KK, Cruz NF, Mrak RE, Dienel GA. Trafficking of glucose, lactate, and amyloid-beta from the inferior colliculus through perivascular routes. J Cereb Blood Flow Metab. 2010;30:162-76.

63. Wang P, Olbricht WL. Fluid mechanics in the perivascular space. J Theor Biol. 2011;274:52-7.

64. Hawkes CA, Sullivan PM, Hands S, Weller RO, Nicoll JA, Carare RO. Disruption of arterial perivascular drainage of amyloid-beta from the brains of mice expressing the human apoe epsilon4 allele. PLoS One. 2012;7:e41636.

65. Sakai K, Boche D, Carare R, Johnston D, Holmes C, Love S, et al. Abeta immunotherapy for alzheimer's disease: effects on apoe and cerebral vasculopathy. Acta Neuropathol. 2014;128:777-89.

66. Rolyan H, Feike AC, Upadhaya AR, Waha A, Van Dooren T, Haass C, et al. Amyloid-beta protein modulates the perivascular clearance of neuronal apolipoprotein e in mouse models of alzheimer's disease. J Neural Transm. 2011;118:699-712.

67. Zekonyte J, Sakai K, Nicoll JA, Weller RO, Carare RO. Quantification of molecular interactions between apoe, amyloid-beta (abeta) and laminin: relevance to accumulation of abeta in alzheimer's disease. Biochim Biophys Acta. 1862;2016:1047-53.

68. Miyata M, Smith JD. Apolipoprotein e allele-specific antioxidant activity and effects on cytotoxicity by oxidative insults and beta-amyloid peptides. Nature Genet. 1996;14:55-61.

69. Craggs L, Taylor J, Slade JY, Chen A, Hagel C, Kuhlenbaeumer G, et al. Clusterin/apolipoprotein $\mathrm{j}$ immunoreactivity is associated with white matter damage in cerebral small vessel diseases. Neuropathol Appl Neurobiol. 2016:42:194-209.

70. Boncoraglio GB, Piazza F, Savoiardo M, Farina L, DiFrancesco JC, Prioni S, et al. Prodromal alzheimer's disease presenting as cerebral amyloid angiopathy-related inflammation with spontaneous amyloid-related imaging abnormalities and high cerebrospinal fluid anti-abeta autoantibodies. J Alzheimers Dis. 2015;45:363-7.

71. Diem AK, Tan M, Bressloff NW, Hawkes C, Morris AW, Weller RO, et al. A simulation model of periarterial clearance of amyloid-beta from the brain. Frontiers Aging Neuroscience. 2016;8:18.
72. Taguchi A, Takata Y, Ihara M, Kasahara Y, Tsuji M, Nishino M, et al. Cilostazol improves cognitive function in patients with mild cognitive impairment: a retrospective analysis. Psychogeriatrics. 2013;13:164-9.

73. Hitscherich K, Smith K, Cuoco JA, Ruvolo KE, Mancini JD, Leheste JR, et al. The glymphatic-lymphatic continuum: opportunities for osteopathic manipulative medicine. J Am Optom Assoc. 2016;116:170-7.

74. Pullen RG, DePasquale M, Cserr HF. Bulk flow of cerebrospinal fluid into brain in response to acute hyperosmolality. Am J Phys. 1987;253:F538-45.

75. Rennels ML, Gregory TF, Blaumanis OR, Fujimoto K, Grady PA. Evidence for a 'paravascular' fluid circulation in the mammalian central nervous system, provided by the rapid distribution of tracer protein throughout the brain from the subarachnoid space. Brain Res. 1985;326:47-63.

76. Iliff JJ, Wang M, Liao Y, Plogg BA, Peng W, Gundersen GA, et al. A paravascular pathway facilitates csf flow through the brain parenchyma and the clearance of interstitial solutes, including amyloid beta. Sci Transl Med. 2012;4:147ra111

77. Kress BT, Iliff JJ, Xia M, Wang M, Wei HS, Zeppenfeld D, et al. Impairment of paravascular clearance pathways in the aging brain. Ann Neurol. 2014;76: 845-61.

78. Xu Z, Xiao N, Chen Y, Huang H, Marshall C, Gao J, et al. Deletion of aquaporin-4 in app/ps1 mice exacerbates brain abeta accumulation and memory deficits. Mol Neurodegener. 2015;10:58.

79. Hoshi A, Yamamoto T, Shimizu K, Ugawa Y, Nishizawa M, Takahashi H, et al. Characteristics of aquaporin expression surrounding senile plaques and cerebral amyloid angiopathy in alzheimer disease. J Neuropathol Exp Neurol. 2012;71:750-9.

80. Zeppenfeld DM, Simon M, Haswell JD, D'Abreo D, Murchison C, Quinn JF, et al. Association of perivascular localization of aquaporin-4 with cognition and alzheimer disease in aging brains. JAMA Neurol. 2017;74:91-9.

81. Louveau A, Smirnov I, Keyes TJ, Eccles JD, Rouhani SJ, Peske JD, et al. Structural and functional features of central nervous system lymphatic vessels. Nature. 2015;523:337-41.

82. Saito S, Kojima S, Oishi N, Kakuta R, Maki T, Yasuno F, et al. A multicenter, randomized, placebo-controlled trial for cilostazol in patients with mild cognitive impairment: the comcid study protocol. Alzheimer's \& Dementia: Trans Res Clin Interven. 2016;2:250-7.

83. Kimura T, Hamazaki TS, Sugaya M, Fukuda S, Chan T, Tamura-Nakano M, et al. Cilostazol improves lymphatic function by inducing proliferation and stabilization of lymphatic endothelial cells. J Dermatol Sci. 2014;74:150-8.

84. Shen Y, Lue L, Yang L, Roher A, Kuo Y, Strohmeyer R, et al. Complement activation by neurofibrillary tangles in alzheimer's disease. Neurosci Lett. 2001;305:165-8.

85. Bradt BM, Kolb WP, Cooper NR. Complement-dependent proinflammatory properties of the alzheimer's disease beta-peptide. J Exp Med. 1998;188: 431-8.

86. Walker DG, Dalsing-Hernandez JE, Lue LF. Human postmortem brainderived cerebrovascular smooth muscle cells express all genes of the classical complement pathway: a potential mechanism for vascular damage in cerebral amyloid angiopathy and alzheimer's disease. Micro Res. 2008;75:411-9.

87. Lian $\mathrm{H}$, Litvinchuk A, Chiang AC, Aithmitti N, Jankowsky JL, Zheng H. Astrocyte-microglia cross talk through complement activation modulates amyloid pathology in mouse models of alzheimer's disease. J Neurosci. 2016;36:577-89.

88. Wyss-Coray T, Yan F, Lin AH, Lambris JD, Alexander JJ, Quigg RJ, et al. Prominent neurodegeneration and increased plaque formation in complement-inhibited alzheimer's mice. Proc Natl Acad Sci U S A. 2002;99: 10837-42.

89. Crehan H, Hardy J, Pocock J. Microglia, alzheimer's disease, and complement. Int J Alzheimers Dis. 2012;2012:983640.

90. Rogers J, Li R, Mastroeni D, Grover A, Leonard B, Ahern G, et al. Peripheral clearance of amyloid beta peptide by complement c3-dependent adherence to erythrocytes. Neurobiol Aging. 2006;27:1733-9.

91. Lambert JC. Genome-wide association study identifies variants at clu and cr1 associated with alzheimer's disease. Nat Genet. 2009;41:1094-9.

92. Chibnik LB, Shulman JM, Leurgans SE, Schneider JA, Wilson RS, Tran D, et al. $\mathrm{Cr} 1$ is associated with amyloid plaque burden and age-related cognitive decline. Ann Neurol. 2011;69:560-9.

93. Farfel JM, Yu L, Buchman AS, Schneider JA, De Jager PL, Bennett DA. Relation of genomic variants for alzheimer disease dementia to common neuropathologies. Neurology. 2016;87:489-96. 
94. Biffi A, Shulman JM, Jagiella JM, Cortellini L, Ayres AM, Schwab K, et al. Genetic variation at $\mathrm{cr} 1$ increases risk of cerebral amyloid angiopathy. Neurology. 2012;78:334-41.

95. Brouwers N, Van Cauwenberghe C, Engelborghs S, Lambert JC, Bettens K, Le Bastard $\mathrm{N}$, et al. Alzheimer risk associated with a copy number variation in the complement receptor 1 increasing $\mathrm{c} 3 \mathrm{~b} / \mathrm{c} 4 \mathrm{~b}$ binding sites. Mol Psychiatry. 2012;17:223-33.

96. Jacquet M, Lacroix M, Ancelet S, Gout E, Gaboriaud C, Thielens NM, et al. Deciphering complement receptor type 1 interactions with recognition proteins of the lectin complement pathway. J Immunol. 2013;190:3721-31.

97. Larvie M, Shoup T, Chang WC, Chigweshe L, Hartshorn K, White MR, et al. Mannose-binding lectin binds to amyloid beta protein and modulates inflammation. J Biomed Biotechnol. 2012;2012:929803.

98. Chen CH, Ghiran I, Beurskens FJ, Weaver G, Vincent JA, Nicholson-Weller A, et al. Antibody cr1-2b11 recognizes a non-polymorphic epitope of human cr1 (cd35). Clin Exp Immunol. 2007;148:546-54.

99. Fonseca MI, Chu S, Pierce AL, Brubaker WD, Hauhart RE, Mastroeni D, et al. Analysis of the putative role of $\mathrm{Cr} 1$ in alzheimer's disease: genetic association, expression and function. PLoS One. 2016;11:e0149792.

\section{Submit your next manuscript to BioMed Central} and we will help you at every step:

- We accept pre-submission inquiries

- Our selector tool helps you to find the most relevant journal

- We provide round the clock customer support

- Convenient online submission

- Thorough peer review

- Inclusion in PubMed and all major indexing services

- Maximum visibility for your research

Submit your manuscript at www.biomedcentral.com/submit 